with standard management, reporting that they seemed to be a routine case for junior medical staff and had to wait until the end of regular operating lists for treatment. ${ }^{4}$ Medical management of miscarriage has the potential for resolving some of these issues and may have economic implications by freeing surgical resources for other uses. ${ }^{5}$ Randomised studies comparing medical with surgical management are required to evaluate this new method of treatment.
1 Hertig AT, Livingstone RG. Spontaneous, threatened and habitual abortion: their pathogenesis and treatment. N Engl f Med 1944;26:797-806.

2 Norman JE, Thong KJ, Baird DT. Uterine contractility and induction of abortion in early pregnancy by misoprostol and mifepristone. Lancet 1991;338:1233-6.

3 Bygdeman M, Swahn ML. Prostaglandins and antiprogestins. Acta Obstet Gynecol Scand Suppl 1989;149:13-8.

4 Friedman $T$. Women's experiences of general practitioner management of miscarriage. I R Coll Gen Pract 1989;39:456-8.

5 Reproductive health and mifepristone [editorial]. Lancet 1990;336:1480-1.

(Accepted 28 fanuary 1993)

\section{Severity of inflammation of tympanic membrane as predictor of clinical course of recurrent acute otitis media}

\author{
C L M Appelman, J Q P J Claessen, \\ F W M M Touw-Otten, G J Hordijk, \\ R A de Melker
}

Department of General Practice, University of Utrecht, Bijlhowerstraat 6 , 3511 ZC Utrecht, The Netherlands

C L M Appelman, general practitioner

F W M M Touw-Otten, professor

R A de Melker, professor

Department of Ear, Nose, and Throat Surgery

J Q P J Claessen, resident

GJ Hordijk, professor

Correspondence to

Dr Appelman

$B M 7$ 1993;306:895 predictive of the clinical course. ${ }^{2}$ In this study we
Acute otitis media occasionally has an irregular clinical course in children, who may then benefit from early antibiotic treatment. Prognostic factors are therefore needed to enable clinicians to identify such cases. Recurrence and age between 6 months and 2 years were found to be predictive of an irregular course in acute otitis media, ${ }^{1}$ and the severity of inflammation of the tympanic membrane has also been found to be investigated whether there was good agreement between observers on the severity of inflammation of eardrums in children with recurrent acute otitis media and whether the severity of inflammation is predictive of the clinical course of the condition.

\section{Patients, methods, and results}

We conducted a randomised, placebo controlled, double blind clinical trial in 121 children aged 6 months to 12 years with recurrent acute otitis media. ${ }^{1}$ The general practitioner and the otolaryngologist independently assessed the severity of inflammation of the eardrum by otoscopic examination. Severity of inflammation was classified as grade 1 (hyperaemia at the malleus handle and the annulus of the tympanic membrane, opacification of the eardrum, and light reflex still visible); grade 2 (thickening of the eardrum with complete redness and absence of the light reflex); or grade 3 (bulging or perforated eardrum). To estimate the agreement between the observers each

Number (percentage) of children with irregular clinical course of acute otitis media by age, body temperature, treatment, and severity of inflammation of eardrum as assessed otolaryngologist

\begin{tabular}{|c|c|c|c|}
\hline & \multicolumn{2}{|c|}{ Severity of inflammation } & \multirow[b]{2}{*}{ p Value } \\
\hline & $\begin{array}{c}\text { Moderate } \\
\text { (grades } 1 \text { and 2) }\end{array}$ & $\begin{array}{c}\text { Severe } \\
\text { (grade 3) }\end{array}$ & \\
\hline $\begin{array}{l}\text { Age (years): } \\
\quad<2 \\
\quad \geqslant 2\end{array}$ & $\begin{array}{l}7 / 16(44) \\
6 / 46(13)\end{array}$ & $\begin{array}{l}3 / 8(38) \\
3 / 33(9)\end{array}$ & $0 \cdot 74$ \\
\hline $\begin{array}{l}\text { Initial body tempe } \\
\quad<38 \\
\geqslant 38\end{array}$ & $\begin{array}{l}6 / 43(14) \\
7 / 19(37)\end{array}$ & $\begin{array}{l}4 / 27(15) \\
2 / 14(14)\end{array}$ & 0.54 \\
\hline $\begin{array}{l}\text { Treatment: } \\
\text { Co-amoxiclav } \\
\text { Placebo }\end{array}$ & $\begin{array}{l}5 / 31(16) \\
8 / 31(26)\end{array}$ & $\begin{array}{l}4 / 25(16) \\
2 / 16(13)\end{array}$ & 0.63 \\
\hline Total & $13 / 62(21)$ & $6 / 41(15)$ & \\
\hline
\end{tabular}

^Mantel-Haenszel test. tympanic membrane was considered independently, and the results were adjusted for age ( $<2$ or $\geqslant 2$ years). Agreement was estimated by means of Kendall's $\tau$ B estimator $(>0.75$ excellent, $0 \cdot 58-0.75$ good, $0 \cdot 40-0 \cdot 57$ moderate, $<0.40$ poor $)^{3}$

When the clinical course of the condition was considered in each child, if both eardrums were inflamed the higher grade of inflammation was taken as the value for that child. The child's age $(<2$ or $\geqslant 2)$, the presence of fever at enrolment, and antibiotic treatment were considered as possible confounders. The children were examined again three days later by the general practitioner, and if earache or fever was still present the clinical course of the condition was considered to be irregular. Statistical analysis was done with either the $\chi^{2}$ test or the Mantel-Haenszel technique. ${ }^{4}$

Five children were excluded from the study because they were not examined by both observers. In 16 of the remaining children only one of their eardrums could be seen by both observers, so that results for 216 eardrums were available. The assessments by the otolaryngologist and general practitioner showed moderate agreement for the children aged under $2(\tau=$ $0.57)$ and good agreement for the older children ( $\tau=$ $0.66)$ and for all the children $(\tau=0.64)$.

One of the possible confounding factors was not recorded for 13 children, so results for only 103 children were used to analyse the predictive value of the severity of inflammation of the eardrum. The clinical course of the condition was irregular in 13 $(21 \%)$ of the 62 patients with moderate inflammation and $6(15 \%)$ of the 41 patients with severe inflammation (table). There was no relation between the severity of inflammation and the clinical course of acute otitis media $\left(\chi^{2}\right.$ test, $\left.p=0.58\right)$. None of the possible confounding factors masked a relation between severity of inflammation and the clinical course of the condition (table).

\section{Comment}

The severity of inflammation of the eardrum did not predict the clinical course of acute otitis media over three days even when the observations were stratified by age, initial temperature, and use of antibiotics. We conclude that the appearance of the tympanic membrane does not help in predicting the clinical course of acute otitis media or in making a decision on its medical management.

1 Appelman CLM, Claessen JQPJ, Touw-Otten FWMM, Hordijk GH, de Melker RA. Co-amoxiclay in recurrent acute otitis media: placebo controlled study. BMF 1991;303:1450-2.

2 Glasscock ME, Shambaugh GE. Acute suppurative otitis media. In: Glasscock ME, Shambaugh GE, eds. Surgery of the ear. Philadelphia: W B Saunders, 1990:170-8

3 Siegel S. Nonparametric statistics for the behavioral sciences. Tokyo: McGraw-Hill Kogakusha, 1956

4 Schlesselman J. Case-control studies. New York: Oxford University Press, $1982: 175,177,183,206$ 